\title{
Presidenl's page
}

\author{
Selling atmospheric science
}

Discussion of science with the layman is difficult at best, and discussions of atmospheric research and atmospheric services present especially difficult problems. All humankind must cope with weather and climate, and there is obviously a great desire for improved services-such as warnings and predictions of severe weather, prediction and alleviation of climatic extremes like droughts. Whatever the research we carry on, we can envisage, somewhere near or far down the road, a useful application to which the research will ultimately relate. In order to demonstrate the relevance of atmospheric research and services, in order to show the public that atmospheric research and services are useful, we all face the strong temptation to present the state of the science as more advanced than can actually be proven, or to promise too much too soon. Needless to say, when any of us falls prey to these temptations, the credibility of the entire science is injured.

Nowhere are these questions more relevant than in the realm of weather modification. Almost no one doubts the economic and social importance of rainfall augmentation, hail suppression, fog dissipation, or severe storm abatement. But great controversy continues about just what beneficial modification effects have been demonstrated or are possible. Claims and counterclaims abound. After almost three decades of intense research and operational weather modification activities, only a handful of experiments have demonstrated beneficial effects to the general satisfaction of the scientific community. Because of the potential economic gains, the field has attracted a host of commercial practitioners, many of them knowledgeable and conscientious, but some with less than minimal qualifications and doubtful integrity. Since they are attempting to make a living by their activities, it is obviously difficult to maintain a high degree of objectivity in judging results. Hence credibility suffers. Some scientists in related research have also sometimes succumbed to temptations engendered by honest enthusiasm, by the belief that the byproducts gained in the way of support to research justify the "little white lie," or by budget developments that threaten their programs.

Changnon $(1975)^{1}$ has attempted to diagnose the reasons why, despite recent advances in weather modification, there is decreased funding for it. Among other things he concludes that "weather modification is an immature, uncertain technology unable yet to display a clear potential for producing sizeable alterations and benefits" and there is "a serious lack of information about the socio-economic aspects of weather." These

1 Changnon, S. A., Jr., 1975: The paradox of planned weather modification. Bull. Amer. Meteor. Soc., 56, 27-37. factors, he says, are "coupled with uncertain management (at all levels)." Elsewhere he noted that "the field also still includes quackery and has been noted for overstated claims," and that various patterns of practice among scientists, managers, and agencies of government "have hurt the field because they often led to an oversell and to expectations seldom achieved." While I do not agree entirely with Changnon's diagnosis, I am emphatically in accord with the latter statements.

Indeed, to describe weather modification as a "technology" is to encourage misunderstanding of the state of the weather modification art. The word "technology" implies that the major substantive scientific foundations of the field have been established and therefore that all that is required is to develop and apply techniques. But one of the conclusions of the special AMS study on cloud physics (Braham and Squires, 1974) ${ }^{2}$ was that "the major bottleneck impeding development of useful deliberate weather modification techniques is the lack of an adequate scientific base." Yet, projects are repeatedly sold on the basis of explicit or implicit promises of economic benefits. In some operational weather modification programs, the "technology" has been so well sold that little or no attention is paid to means of scientific evaluation of the results, especially if this requires some sort of randomization, with adequate attention to the integrity of controls.

Despite the generally-acknowledged lack of an adequate scientific base, some enthusiasts believe that we should encourage operational weather modification projects as long as the customer is not promised any particular benefits and there is little risk of harmful side effects. After all, they argue, if the risks are small in comparison to the potential benefits, isn't it worth the gamble? This sounds eminently reasonable; but there is an inevitable and unfortunate result: Whatever disclaimers are made at the outset, the sponsors nearly always entertain expectations of benefits, and these expectations grow with time. As funds are expended, the project leader is often obliged to justify further resources on the basis of results to date, which can lead either to over-stated claims of results or of great benefits to come. And finally, if no definitive results are forthcoming, the customer will tend to forget the original disclaimers and accuse the operator of having sold him a bill of goods. In this and other ways, ill-advised operational weather modification programs bring the field into disrepute and jeopardize meteorology's credibility and base of support. And weather modification is only one of the realms in which we have had suffi-

2 Braham, R. R., and P. Squires, 1974: Cloud physics1974. Bull. Amer. Meteor. Soc., 55, 545-586. 
cient experience to learn to recognize the traps into which unreasonable expectations may lead.

Another difficulty, when discussing atmospheric science and its value, is that so little has been done to appraise the value of present and potential atmospheric science applications. Changnon 3 and others have suggested the need for socio-economic studies of such potential benefits. The importance of such studies cannot be overemphasized, nor should their hazards be minimized. With limited resources for science, it is unrealistic to expect that major programs will be initiated or enlarged without an appraisal of the likely benefits to be derived. Such studies should also aid in establishing the priorities within the discipline. And when, as in weather modification, a potential new technology is involved, we also have the responsibility of assessing harmful side effects, if any.

There are, however, dangers in socio-economic studies. Many of these investigations concentrate on "what if" types of questions, e.g.: "What benefits would accrue if we could forecast the weather or climate $X$ months, years, or even decades ahead?" or "What benefits will accrue from a particular kind of weather modification?" In these cases, some future capability is assumed, even though wo do not know whether the capability can or will be reached. Unless accompanied by realistic appraisals of what capabilities are realistic to expect, "what if" studies may merely give the impression that we are more confident of reaching the capability than we have any right to be. Again, we are raising premature expectations.

3 Op. Cit.
Therefore, we must apply precautions in carrying out and using socio-economic studies. Let us present a spectrum of possible outcomes appropriate to the spectrum of premises, and let us also either estimate a "reality figure" for that spectrum or simply admit that we don't know.

Atmospheric problems of public concern often arise in connection with the potential impact of a new or existing industrial endeavor. The possibility of a serious depletion of ozone as a result of the use of the chlorofluoromethanes in aerosol sprays is a case now receiving public attention. In areas such as this we must avoid scare tactics. We should tell all we know, but no more. Our estimate of the hazards must be as sound as our existing scientific knowledge permits; we must be honest in explaining the limitations in our knowledge, and we must be realistic in describing the scope of research efforts and the time necessary to fill the gaps in the knowledge now available to policy makers.

Therefore let us undertake socio-economic studies to indicate potential worth and environmental impact studies to assess potential harm. But let us not clothe our crystal ball gazing in a shroud of false authenticity. Our problems and concerns must be well-articulated and responsibly stated. Only in this way will we establish our credibility, serve the public good, and faithfully serve the discipline and the profession.

The views stated above are my own and do not necessarily reflect those of the Society. Special appreciation goes to Edwin Wolff of the National Center for Atmospheric Research, Boulder, Colorado, for his assistance with this editorial.-David Atlas, President
(Continued from announcements, page 687)

15-19 September 1975: A Signal Processing Seminar will be held at University Park, Pa., sponsored by the continuing education services of the Pennsylvania State University, College of Engineering Applied Research Laboratory. The seminar will focus on the use of signal processing techniques to analyze mechanical vibrations, speech, underwater sound, radar signals, and seismic signals. Contact: The Pennsylvania State University, $410 \mathrm{~J}$. Orvis Keller Building, University Park, Pa. 16802.

17-19 September 1975: The American Institute of Aeronautics and Astronautics Conference on Exploration of the Outer Planets will take place in St. Louis, Mo., cosponsored by the Technical Committee on Space and Atmospheric Physics, the Technical Committee on Space Systems, and the Section of Planetology of the AGU. Contact: Noel Hinners, Code S, Office of Space Science, NASA Headquarters, Washington, D.C. 20546.

18-19 September 1975: The Sixth Annual Meeting of the Southern Section of the Air Pollution Control Association will be held at the Sheraton-Nashville Hotel, Nashville, Tenn. The tentative program includes technical papers on air pollution control in the aluminum and ferrous metal industry, the Clean Air Act, and a special topics session.
For details contact: Mr. Gordon Nix, Optimal Systems, Inc., P.O. Box 1182, Atlanta, Ga.

22-26 September 1975: An Underwater Acoustics Seminar will be held at University Park, Pa., by the continuing education services of The Pennsylvania State University, College of Engineering Applied Research Laboratory. The seminar will include discussion of sound propagation in the ocean, transducers, oceanographic instruments, the generation and measurement of underwater sound, and calibration techniques. Contact: The Pennsylvania State University, see above.

5-9 October 1975: The American Society for Testing and Materials (ASTM) Committee D-22 on Methods of Sampling and Analysis of Atmospheres will meet in the Sheraton Hotel in Philadelphia, Pa. Contact ASTM, 1916 Race St., Philadelphia, Pa. 19103.

\section{Hurricanes on Texas coast}

A series of three booklets designed to help coastal zone residents understand, prepare for, and recover from the effects of hurricanes has been published by the Texas A\&M Sea Grant College Program. Authors of this series, entitled Hurricanes on the Texas Coast, are Walter K. Henry, Dennis

(More announcements on page 703) 


\section{ARE YOU ENERGY-ORIENTED?}

If you're looking for answers-in the wind, sun, or water-we can help you select instruments that will meet your technical specifications and your budget.

Write for our revised literature $\cdot$ Sections $3,4,5$, \& 6 CATG 9 are off the press, more sections are in preparation.

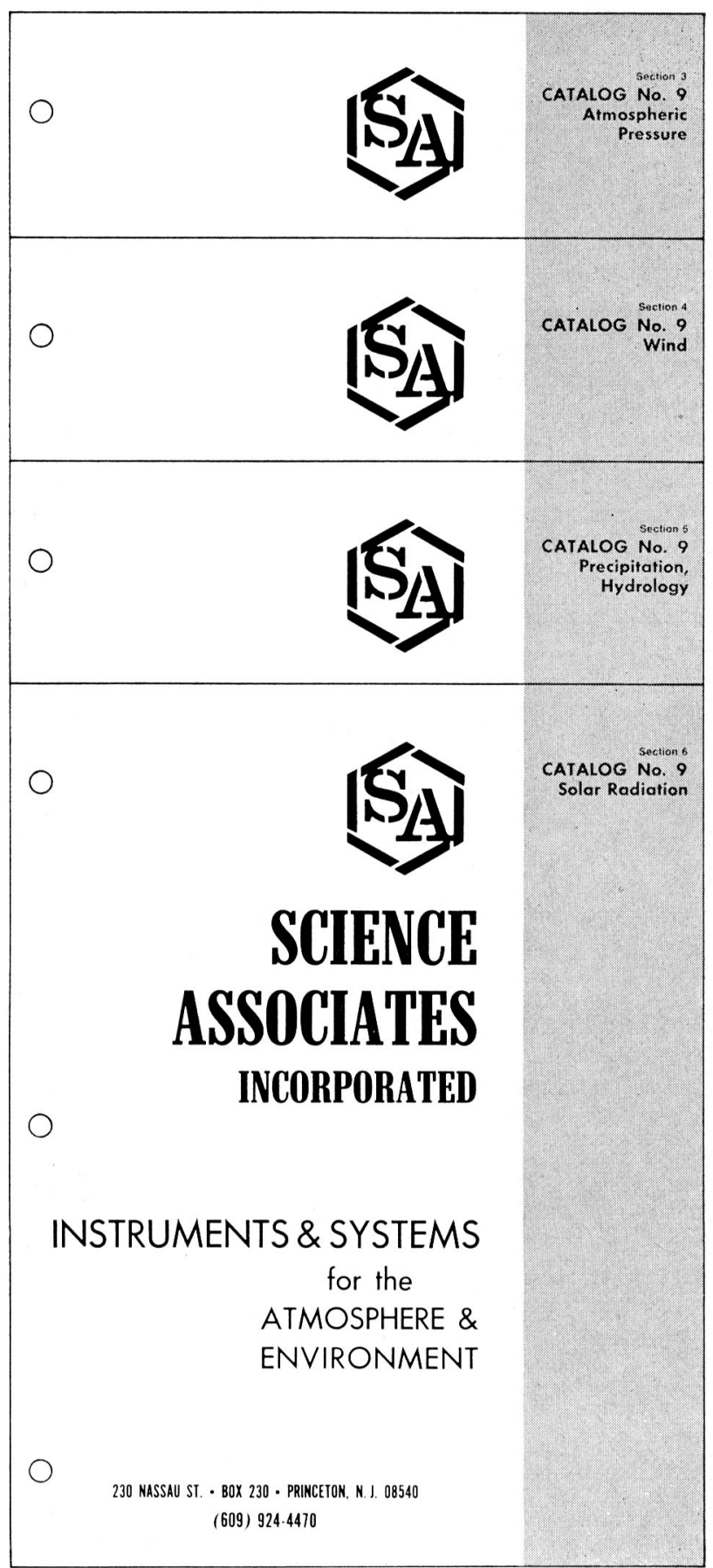

